\title{
Roughness-Controlled $\mathrm{Cu}_{2} \mathrm{ZnSn}(\mathrm{S}, \mathrm{Se})_{4}$ Thin Film
}

\section{Solar Cells with Reduced Charge Recombination}

Ki beom Cheon,,$^{\dagger}$ Sun Kyung Hwang,,$^{\dagger}$ Se Won Seo, ${ }^{\dagger}$ Jae-Hyun Park,,$+\not+$ Min-Ah Park,,$^{\dagger}$ and Jin Young Kim $^{+,+*}$

$\uparrow$ Department of Materials Science and Engineering, Seoul National University, Seoul 08826, Republic of Korea

† Research Institute of Advanced Materials (RIAM), Seoul National University, Seoul 08826, Republic of Korea

*Corresponding author: jykim.mse@snu.ac.kr, Tel: +82 2 8808315, Fax: +82 28859671 

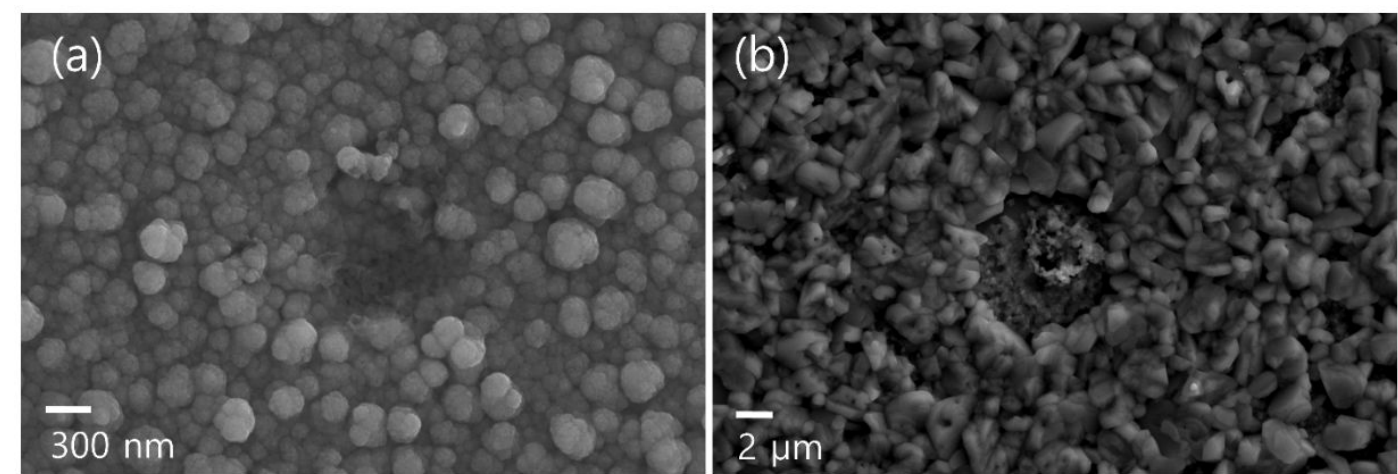

Figure S1. Fault at the film caused by hydrogen bubble. (at $t_{i}=30 \mathrm{~s}$ condition) (a) as-deposited CZT alloy film, (b) CZTSSe films after annealing 

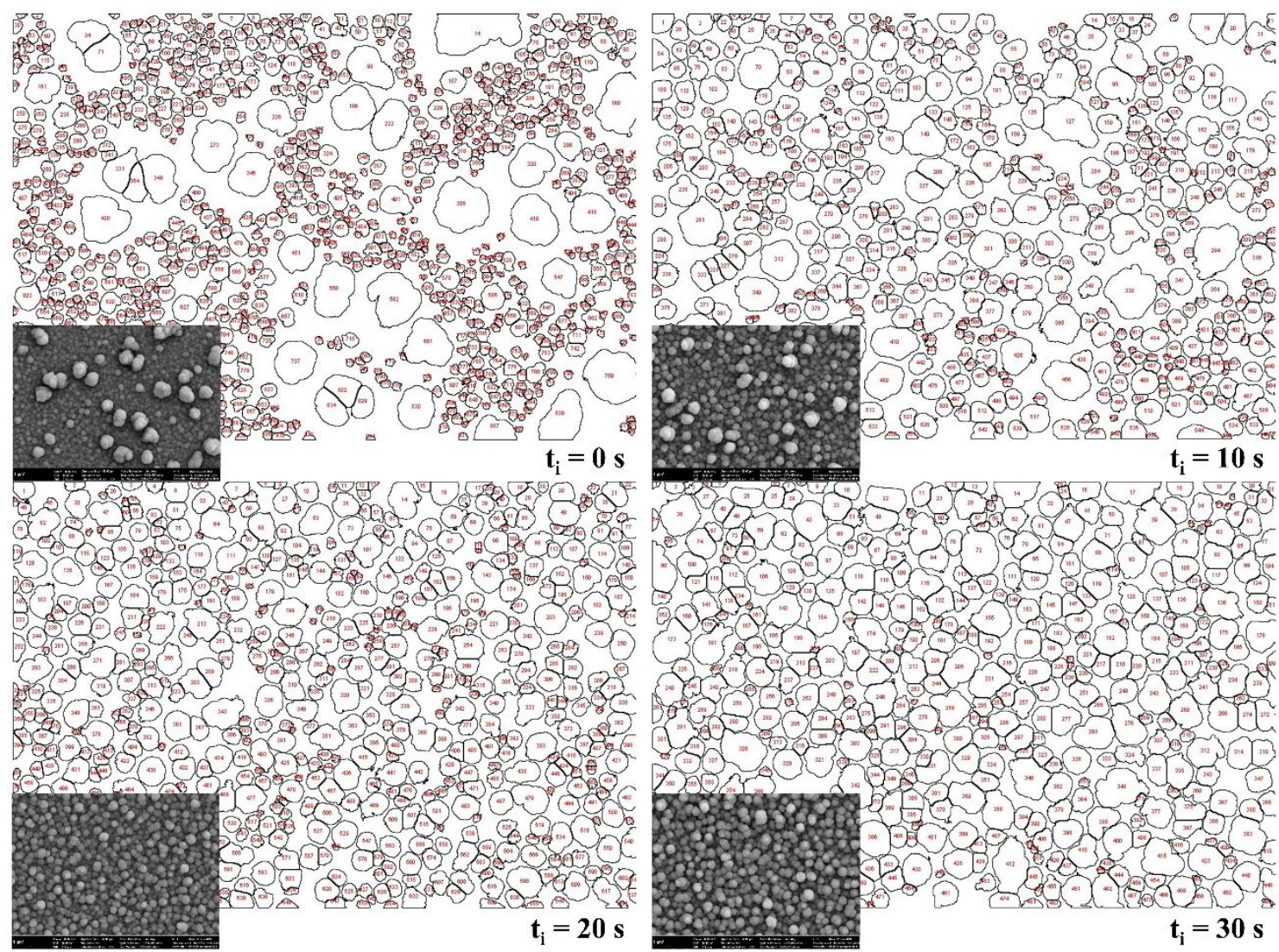

Figure S2. Particle size analysis (in area) from the imageJ software. 

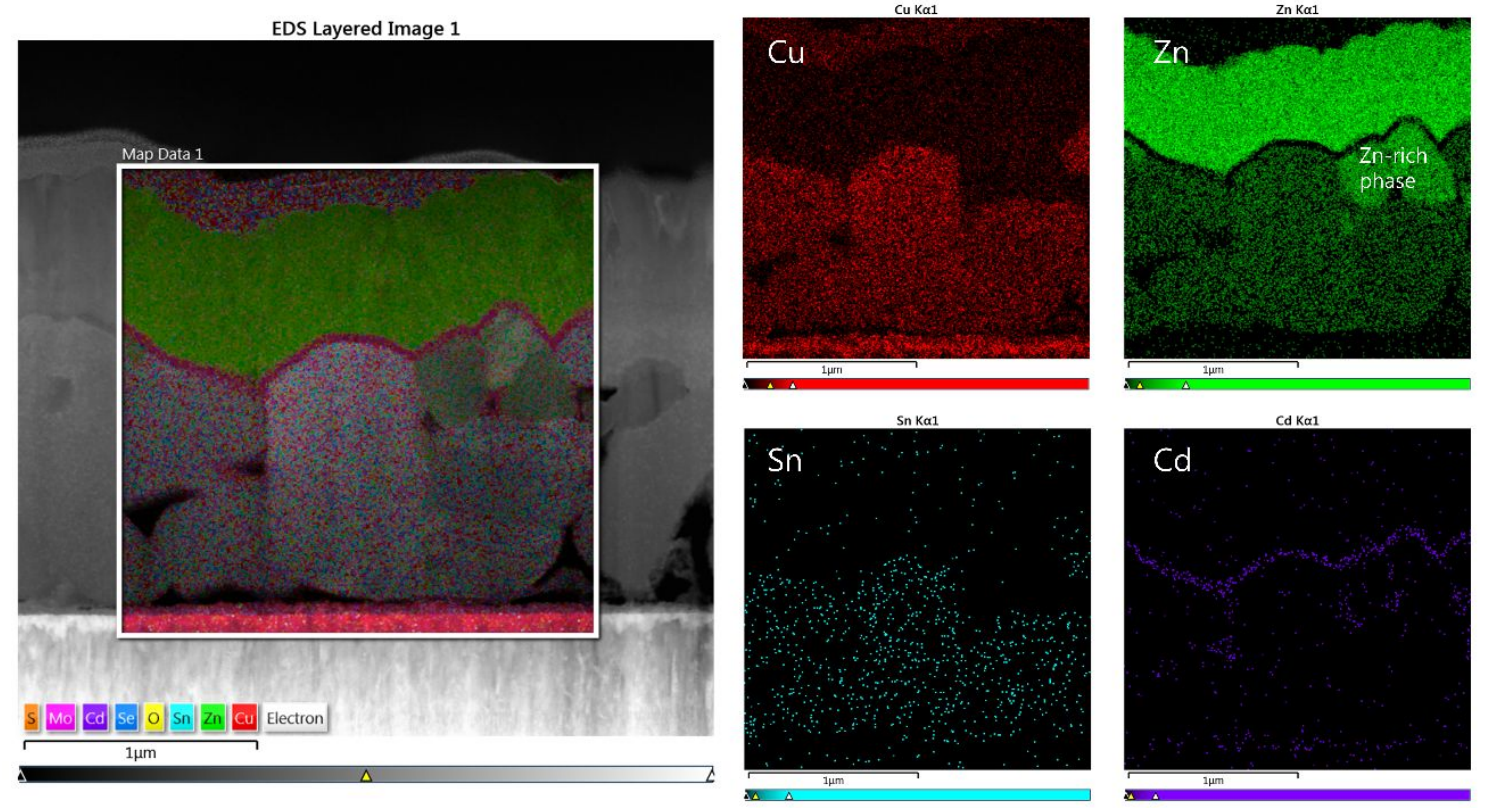

Figure S3. EDS mapping of the crosssection. Integrated image, signals of each ion species, $\mathrm{Cu}, \mathrm{Zn}$, $\mathrm{Sn}$, and $\mathrm{Cd}$ 


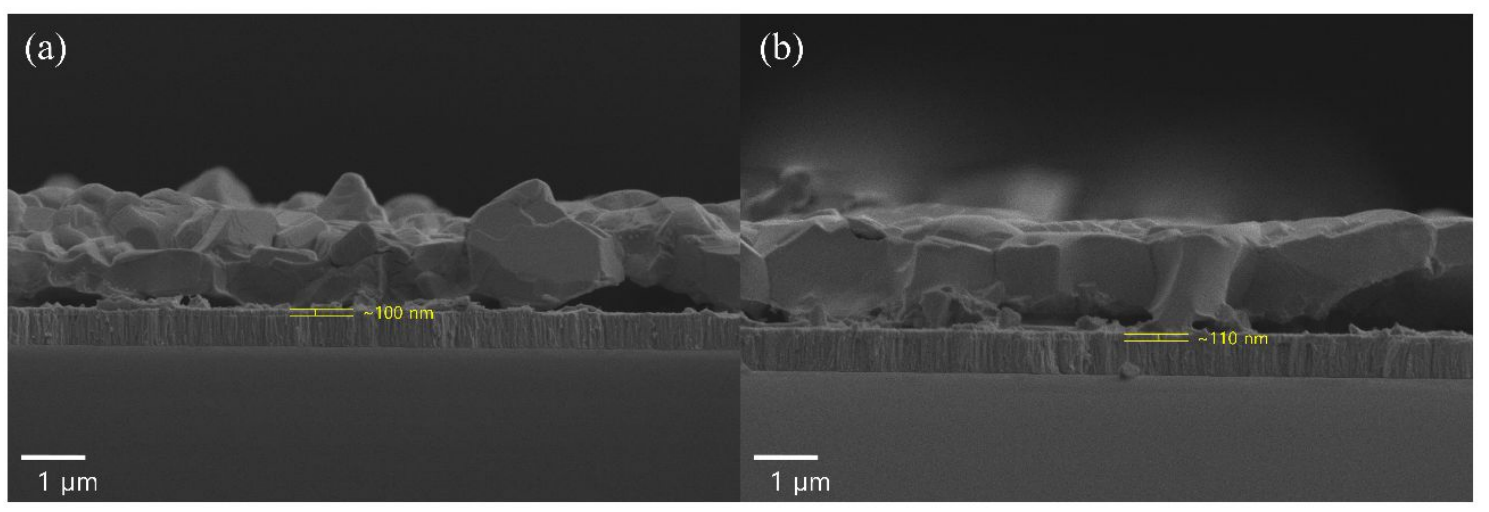

Figure S4. MoS thickness of annealed CZTSSe films (a) $t_{i}=0 \mathrm{~s}$, (b) $t_{i}=30 \mathrm{~s}$ 


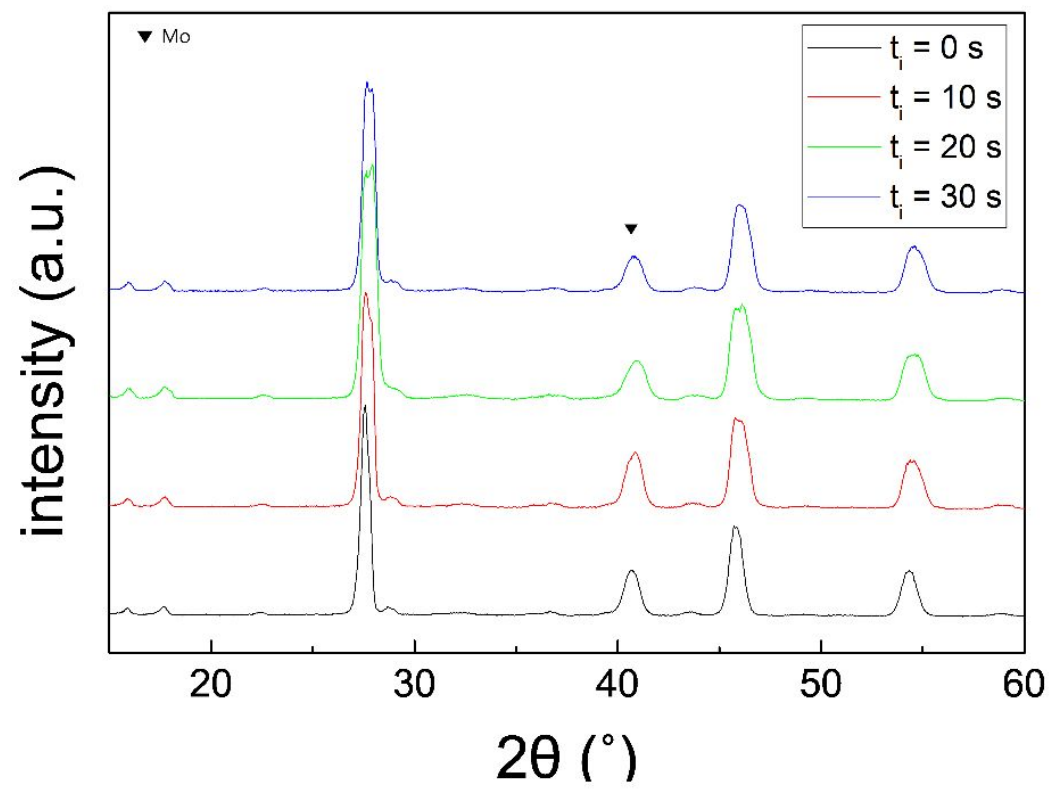

Figure S5. GIXRD pattern of annealed CZTSSe films (measured with $\omega=3^{\circ}$ ). 

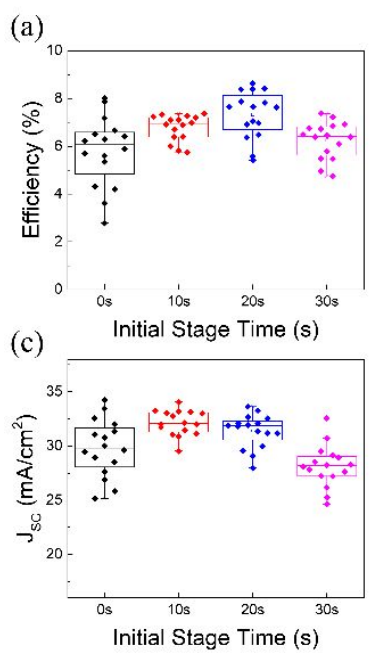

(b)

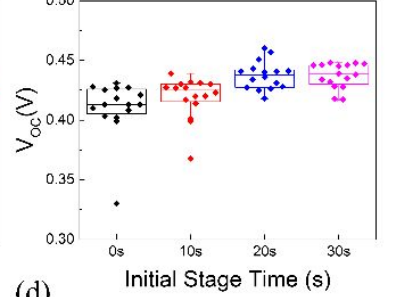

(d)

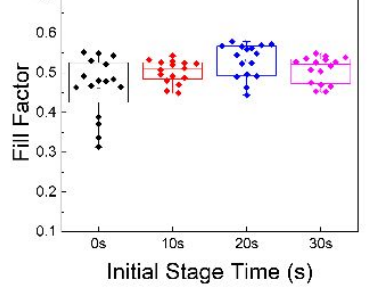

(e)

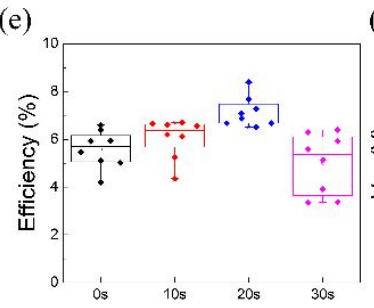

(f)

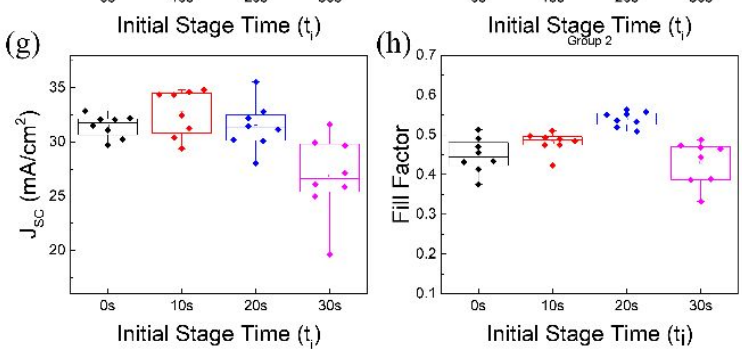

Figure S6. Statistical box plots of cell performances and factors depending on $t_{i}=(0 \mathrm{~s}, 10 \mathrm{~s}, 20$

s, 30 s). (a) (d) Applied current density: $-3.92 \mathrm{~mA} \mathrm{~cm}^{-2} /-1.45 \mathrm{~mA} \mathrm{~cm}^{-2}$ (e) $\sim$ (h) Applied current density: $-3.92 \mathrm{~mA} \mathrm{~cm}-2 /-1.35 \mathrm{~mA} \mathrm{~cm}^{-2}$ for each stage. $\left(1^{\text {st }} / 2^{\text {nd }}\right)$ 


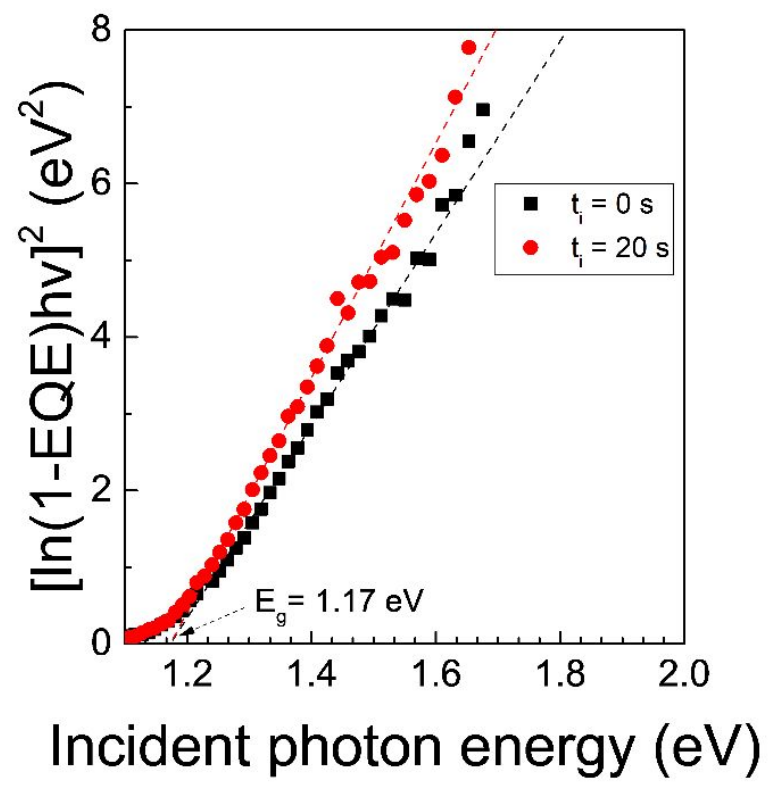

Figure S7. Band gap energy estimated from the measured EQE spectra, which were about $1.17 \mathrm{eV}$ for both cases $\left(t_{i}=0 \mathrm{~s} / t_{i}=20 \mathrm{~s}\right)$. 
(a)

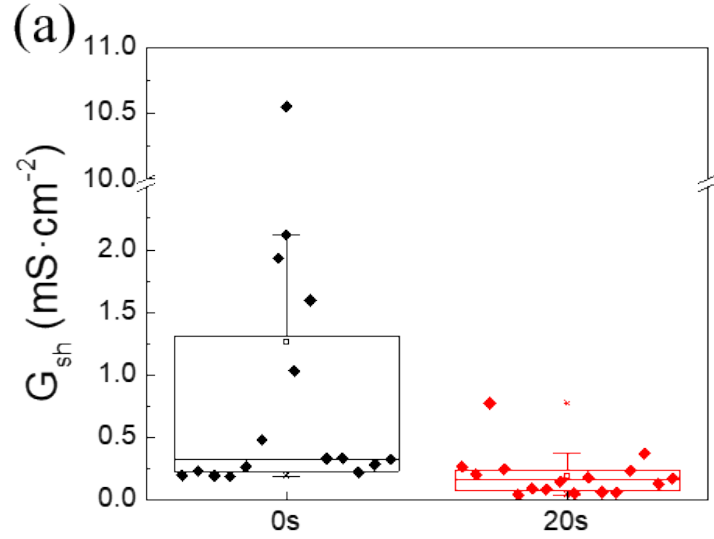

Initial Stage Time (s)

(c)

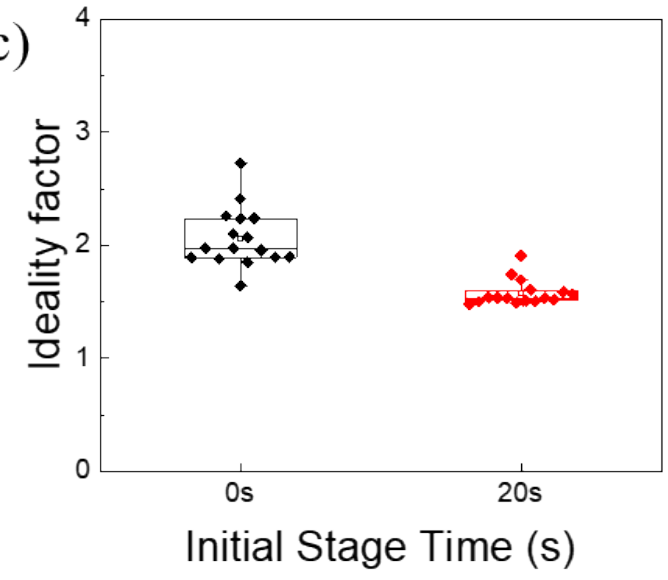

(b)

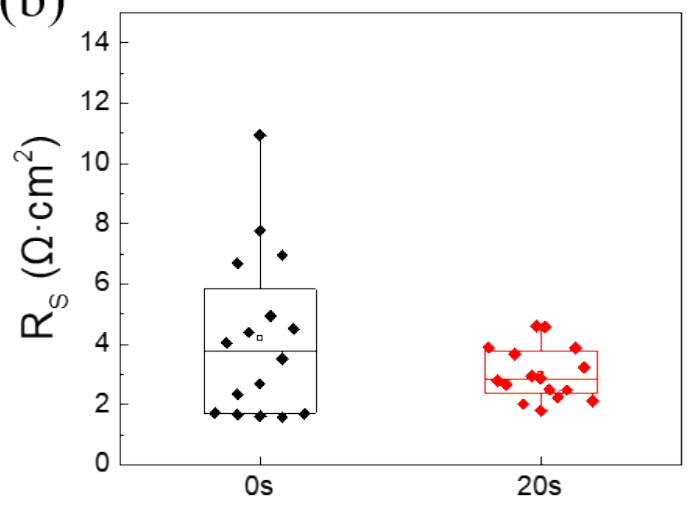

Initial Stage Time (s)

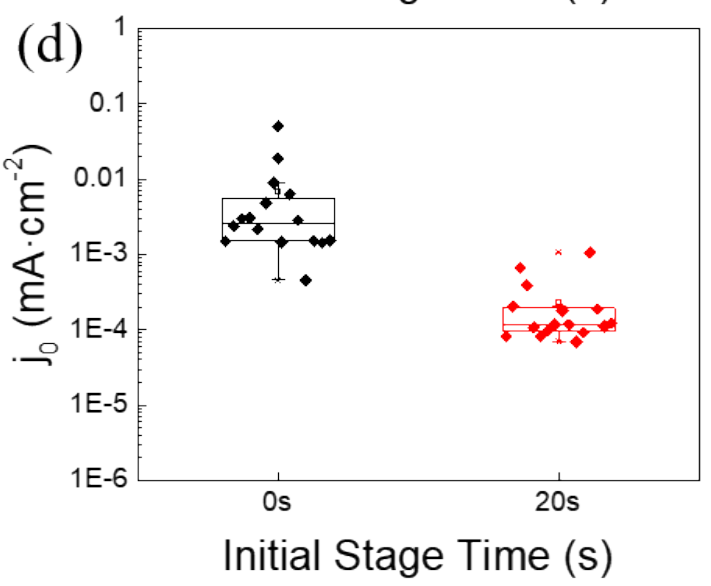

Figure S8. Statistical box plots of diode parameters depending on $t_{i}=0 s((a)$ Shunt conductance (b) Series resistance (c) Ideality factor (d) Dark saturation current). 
(b)

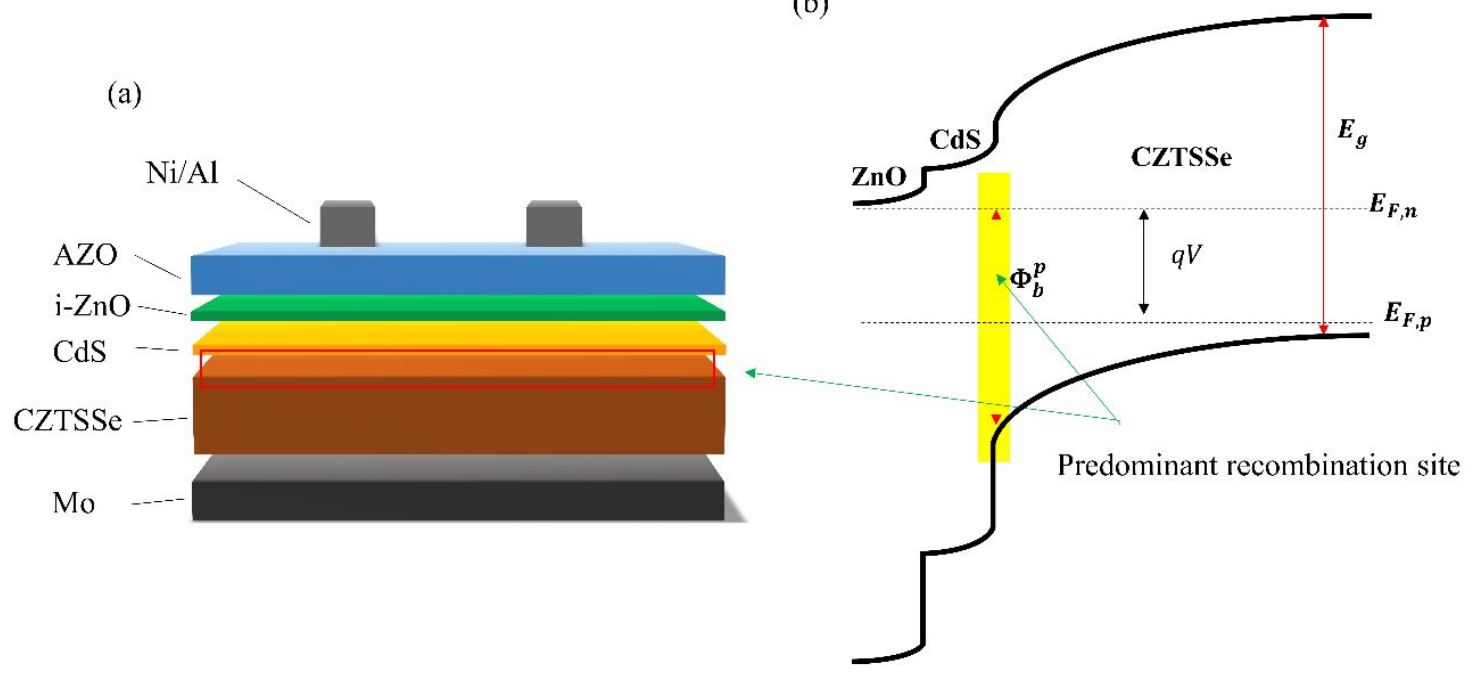

Figure S9. Schematic (a) device structure and (b) band diagram of CZTSSe solar cell. Activation energy $\left(E_{a}\right), y$-intercept of the extrapolated $V_{O C}-T$ plot, approaches to band gap energy $\left(E_{g}\right)$ if bulk recombination is dominant, and approaches to barrier height $\left(\Phi_{b}{ }^{p}\right)$ if interface recombination is dominant. 